\title{
Teacher Self-Efficacy for Teaching Students with Autism Spectrum Disorder: Associations with Stress, Teacher Engagement, and Student IEP Outcomes Following X Consultation
}

\author{
Abigail M. A. Love \\ Jordan A. Findley \\ Lisa A. Ruble \\ University of Kentucky \\ John H. McGrew \\ Indiana University-Purdue University Indianapolis
}

\begin{abstract}
Author Note
The following authors are affiliated with the University of Kentucky; Abigail M. A.

Love, Department of Educational, School, and Counseling Psychology, amlove2@uky.edu;

Jordan A. Findley, Department of Educational, School, and Counseling Psychology,

jordan.findley@uky.edu; Lisa A. Ruble, Department of Educational, School, and Counseling

Psychology, lisa.ruble@uky.edu. John H. McGrew is affiliated with Indiana University - Purdue

University Indianapolis,jmcgrew@iupui.edu.

This work was supported by Grant 1RC1MH089760 from the National Institute of

Mental Health. Correspondence concerning this article should be addressed to Abigail M. A.

Love; amlove2@uky.edu, 347 Scott Street, Dickey Hall University of Kentucky, Lexington, KY, 40508.
\end{abstract}

This is the author's manuscript of the article published in final edited form as:

Love, A. M. A., Findley, J. A., Ruble, L. A., \& McGrew, J. H. (2020). Teacher Self-Efficacy for Teaching Students With Autism Spectrum Disorder: Associations with Stress, Teacher Engagement, and Student IEP Outcomes Following COMPASS

Consultation. Focus on Autism and Other Developmental Disabilities, 35(1), 47-54. https://doi.org/10.1177/1088357619836767 
Teacher Self-Efficacy for Teaching Students with Autism Spectrum Disorder: Associations with Stress, Teacher Engagement, and Student IEP Outcomes Following X Consultation Although teachers reporting high teaching self-efficacy demonstrate positive teaching behaviors, minimal stress, and superior classroom management techniques, surprisingly few studies have demonstrated a relationship between teacher self-efficacy and student outcomes (Zee \& Koomen, 2016). This study explored self-efficacy specific to teaching students with ASD, and examined relationships with stress, teacher engagement, and student IEP outcomes. Special education teachers $(N=44)$ were recruited as part of a larger study examining a consultation intervention. Results indicated that self-efficacy for teaching students with ASD was significantly and positively correlated with teacher engagement and student outcomes, and negatively correlated with teacher stress. Further, teachers that received the consultation intervention reported higher levels of self-efficacy for teaching students with ASD. This is the first study to report a direct association between teacher self-efficacy and student IEP outcomes and the potential positive impact of a teacher consultation intervention on the teacher intrapersonal factor of self-efficacy.

Keywords: Teacher self-efficacy, autism spectrum disorder, teacher stress, teacher engagement, social cognitive theory 
Teacher Self-Efficacy for Teaching Students with Autism Spectrum Disorder: Associations with Stress, Teacher Engagement, and Student IEP Outcomes Following X Consultation

Because special education serves students representing a wide variety of physical, emotional and cognitive disabilities, there is often substantial heterogeneity in students' needs, goals, and learning outcomes. Across special education student populations, learners with autism spectrum disorder (ASD) are described as one of the most challenging groups for teachers (White, Smith, Smith, \& Stodden, 2012). A critical factor impacting students' educational outcomes is teachers' skills and abilities when intervening across students (Tefera, Thorius, \& Artiles, 2014). However, understanding the nature of teacher influence is challenging because teaching effectiveness is related to numerous variables that reciprocally impact one another. Researchers interested in understanding the correlates of instructional effectiveness have identified teacher's pedagogical knowledge as well as personal factors such as emotions, engagement, and beliefs (Anderman \& Klassen, 2015; Ruble, Toland, Birdwhistell, McGrew, \& Usher, 2013). One particular factor that has gained attention because of its impact on student outcomes is a teacher's beliefs in his or her own skills, or teacher self-efficacy. Grounded in Bandura's (1997) social cognitive theory, teacher beliefs are viewed as proximate predictors of behavior, and are both influencing and influenced by environmental and behavioral factors. Teacher beliefs have an effect on student outcomes because teachers with higher selfefficacy demonstrate more effective lesson plans, classroom management techniques, and integration of student engagement because they "believe that difficult students are teachable through extra effort and appropriate techniques..." (Bandura, 1997, p. 241). 
Teachers' beliefs about efficacy potentially impact the approach to all learning experiences, and therefore can play a lead role in guiding behaviors in designing the teaching environment and on acts within that environment (Fives \& Buehl, 2008; Pajares, 1996). As Bandura (1997) explicitly noted, "People's level of motivation, affective states, and actions are based more on what they believe than on what is objectively true" (p. 2). In other words, increased incentive to act, or motivation, can be attributed not only to skills, knowledge, or experience, but also more powerfully to self-efficacy (Bandura, 1997; Ruble et al., 2011). Because of their potential impact on teachers' choices, behaviors, and decisions in the classroom that directly affect student learning, investigations into these beliefs, therefore, can lead to greater understanding of how to increase student achievement and outcomes.

Teaching self-efficacy has been widely investigated and has been identified as an important predictor of positive teacher and student outcomes (Klassen \& Tze, 2014; Zee \& Koomen, 2016). As noted by Zee and Koomen (2016) in their review of research from 19702016, teacher self-efficacy has been analyzed using a range of methods, sample sizes, and instruments and the relationship with student outcomes has been examined both with respect to overall student achievement and to domain-specific student achievement (e.g., math achievement). For example, Zee and Koomen (2016) cited eight studies linking teacher selfefficacy to students' overall achievement (measured by school grades), although two of those studies utilized sample sizes less than 20 (Allinder, 1995; Ross, 1992). Similarly, a total of fourteen studies linked teacher self-efficacy to domain-specific performance measures including literacy and math (Zee \& Koomen, 2016). Zee and Koomen also reviewed potential moderators of self-efficacy, noting, for example, that teacher self-efficacy has more effect on certain students according to age (e.g., younger students are more strongly effected by teacher self-efficacy) and 
subject domain. However, one glaring gap in their review, was the lack of research addressing the association between teacher self-efficacy and achievement of students in special education. In part, this may be because standardized student achievement measures are not appropriate for measuring progress for a student with an individualized teaching plan (Ruble, McGrew, \& Toland, 2012). Therefore, the goal of the current study was to examine the relationship between teacher self-efficacy and a measure of student outcomes that is sensitive to the assessment of progress for those with individualized education programs (IEPs).

Thus, for this study, we applied a greater degree of specificity by examining self-efficacy beliefs of teachers, teacher engagement, teacher stress, and student outcomes for students aged 3 to 8 with ASD. Understanding more about what a teacher believes about her capabilities to teach these particular learners can lead to more effective interventions, greater support, and better knowledge for improving the educational experience and outcomes of students with ASD. Current research on self-efficacy for teaching students with ASD is preliminary at best, with only four studies directly addressing self-efficacy for teachers working with students with autism (Jennett, Harris, \& Mesibov, 2003; Ruble et al., 2013; Ruble et al., 2011; Segall \& Campbell, 2014). One methodological issue complicating the research is how best to measure self-efficacy. Jennett and colleagues (2003) measured teacher self-efficacy using a modified version of the Teacher Efficacy Scale for special educators (Coladarci \& Breton, 1997) and their commitment to a teaching philosophy (ABA vs. TEACCH). Teachers who reported a strong commitment to a particular philosophy also reported greater teaching self-efficacy (Jennett et al., 2003). Segall and Campbell (2014) examined educational placement decisions made by teachers for students with ASD as it related to general teaching self-efficacy across six domains. Results suggested greater teacher self-efficacy was related to placement decisions, an increased 
knowledge of students with ASD, and a decreased perception of disruptive behaviors (Segall \& Campbell, 2014). Following a preliminary investigation into self-efficacy among teachers of students with autism that found a negative relationship between self-efficacy for classroom management and burnout (Ruble, Usher, McGrew, 2011), Ruble and colleagues (2013) developed an ASD-specific measure of self-efficacy for teaching students, the Autism SelfEfficacy Scale for Teachers (ASSET). They concluded that ASSET was a valid and reliable instrument for assessing self-efficacy within the ASD population and also reported negative correlations between teacher self-efficacy for autism and teacher burnout (Ruble et al., 2013). However, with the exception of Ruble et al., 2013, these studies utilized a teacher self-efficacy instrument that was not specific to the population of learners it was trying to examine (i.e., students with ASD). This is a concern because self-efficacy is domain-specific, and failure to use appropriate instrumentation may result in Type II error or false positive results that require cautious interpretation (Zee \& Koomen, 2016).

A further limitation of the extant literature is that it has tended to study self-efficacy in isolation, untethered from its theoretical underpinnings and ignoring factors thought to impact it. According to Bandura (1997), there are four sources of self-efficacy: mastery experiences, vicarious experiences, social persuasions, and physiological/affective state (see Usher \& Pajares, 2008 for a review). Thus, to provide greater understanding of the complex factors that impact self-efficacy and student outcomes, we considered the sources of self-efficacy. The sample of teachers used for this study took part in a randomized controlled trial (RCT) of a consultation intervention for student's with ASD (REMOVED), which included attention to three of these sources: mastery experiences, social persuasions, and physiological/affective state. The (REMOVED) consultation intervention is comprised of an initial assessment, goal-setting, and 
intervention planning meeting that includes the special education teacher, parent, and consultant. Following this initial meeting are four, 1 to 1.5 hour, teacher coaching sessions spread evenly throughout the remaining school year. In total, the consultant spends less than 10 hours with the teacher over the school year. Compared to the control group, students in the experimental group had greater goal attainment with a large effect size when delivered face-to-face $(d=1.1-1.4$; REMOVED) or via a web-based approach ( $d=1.1$; REMOVED).

Although the intervention is not aimed at increasing self-efficacy for teaching students with ASD specifically, it was our hypothesis that the $X$ consultation intervention would improve self-efficacy for teaching students with ASD because included in its procedures are activities that tap into three out of the four sources of self-efficacy. Throughout the consultation, mastery experiences are provided when teachers are guided through the use of reflective feedback and self-monitoring during coaching sessions to evaluate implementation of teaching plans and to try new methods and strategies specific to support their students. Social persuasions are a natural occurrence in a consultation intervention, as the consultant provides feedback and encouragement to the teacher throughout the intervention. Finally, the teacher's physiological arousal and anxiety may decrease when given support with challenging students, and over time this is thought to produce lower levels of overall stress and burnout. As noted above, the authors of the (REMOVED) consultation have established its success in improving progress on IEP goals. In the current study, we were interested both in whether the intervention also improved teacher self-efficacy and in the connection between self-efficacy and IEP progress.

Specifically, we hoped to add to the current literature by studying teacher self-efficacy within special education, with a narrowed focus on teachers who work with students with ASD. We investigated special education teachers who were responsible for implementing the IEPs of 
at least one child who has ASD and evaluated the strength of relationship between teacher selfefficacy and student IEP outcomes. We also examined the relationship between teacher selfefficacy and teacher stress and engagement, as both constructs have been shown to be influenced by teacher self-efficacy.

Our primary research question asked about the relationships between self-efficacy for teaching students with ASD and teacher stress, teacher engagement, and student IEP outcomes. In a replication of Ruble and colleagues (2013), we hypothesized that self-efficacy for teaching students with autism would be negatively associated with teacher stress. In addition, consistent with findings on student outcomes and self-efficacy in other student groups (Zee \& Koomen, 2016), we hypothesized that teacher self-efficacy would be positively associated with IEP progress. Lastly, based on the reasonable supposition that teachers who believe they have the skills for teaching students with ASD should also demonstrate an increased amount of engagement, together with prior findings of a relationship between student engagement and selfefficacy (Zee \& Koomen, 2016), we hypothesized that teacher engagement and self-efficacy would be positively related.

As a secondary goal, we examined differences in teacher self-efficacy scores based on participation in the (REMOVED) consultation or self-instruction using online training in three evidenced based practices and asked: Does a consultation intervention have an effect on teacher's reported levels of self-efficacy for teaching students with ASD? We hypothesized that teachers who received (REMOVED) consultation would report higher levels of self-efficacy for teaching students with ASD.

\section{Method}

\section{Intervention}


The data were derived from a randomized controlled trial of (REMOVED). Special education teachers completed measures both at baseline, before randomization, and at the end of the school year (REMOVED). The study spanned one school year (August - May). For this study, the data analyzed were those collected at the end of the school year (May).

\section{Participants}

Special education teachers with at least one student with ASD on their caseload from participating school districts from one of two mid-southern states were approached to participate in the parent study. Forty-four child-teacher dyads met the inclusion criteria and agreed to participate (See Table 1). When multiple students with ASD were on a teacher's caseload, one student was randomly selected to participate. Child-teacher dyads were randomized into one of three approximately equal sized conditions, a control condition receiving online training on three evidence-based practices in autism, an experimental condition receiving the (REMOVED) initial consultation and coaching sessions delivered face-to-face, and an experimental condition receiving the (REMOVED) initial consultation face-to-face and the coaching sessions delivered online. Students were required to be diagnosed with ASD according to the Diagnostic and Statistical Manual of Mental Disorders ( $4^{\text {th }}$ ed., TR; American Psychiatric Association, 2000) as confirmed by the Autism Diagnostic Observation Schedule (Modules 1 or 2; Lord et al., 2000), a standard diagnostic instrument for identifying individuals with autism. In addition, all students were served under the autism eligibility category with the Individuals with Disabilities Education Act (IDEA; 2004). The mean age of students with ASD was $5.7(S D=1.5)$. Informed consent and, when possible, assent was obtained from all participants. The Institutional Review Board approved all study procedures.

\section{Measures}


Autism self-efficacy scale for teachers (ASSET). The ASSET is a 30-item self-report measure of teachers' beliefs about their ability to implement appropriate teaching strategies when working with students with ASD (Ruble et al., 2013). Teachers were asked to rate their efficacy to carry out several different assessment, intervention, and classroom-based practices relevant to the needs of students with ASD. Items included in the ASSET were developed based on a selfreport questionnaire used as part of a Midwestern state teacher training in ASD and by best practices outlined by the National Research Council (2001). Teachers rated their self-efficacy to execute a range of duties regarding a specific student with ASD in their class using a scale from 0 (cannot do at all) to 100 (highly certain can do). The 100-point rating scale was used based on Bandura's (2006) guidelines for constructing self- efficacy scales. The total score was calculated as the mean score across the 30 items. Scale internal consistency was .96 . Total scores were used for all data analyses (higher total scores demonstrating higher self-efficacy beliefs).

Teacher engagement rating scale (TERS). The TERS consists of 6 items: 1) Level of Affect, which measures the teacher's interest in/attention to the student or his/her activity; 2) Maintenance of Interaction, which measures degree to which the teacher builds on the student's initiation and/or assists the student in using objects functionally; 3) Directiveness, which measures degree to which the teacher gives commands and/or directs the student's immediate attention; 4) Responsiveness, which measures frequency and intensity of the teacher's reactions to student's initiation with actions or objects; 5) Initiation, which measures the degree to which the teacher begins interaction with student; and 6) Level of Movement/Participation, which measures degree to which the teacher stays on the student's physical level (Ruble et al., 2005). Blind observers scored videotapes of teachers interacting with their student with ASD for the final teacher engagement score. Teacher engagement was rated on a 1 (does not attempt) to 3 
(maintained throughout) Likert-type response scale, increasing in half point increments. Higher scores indicate higher levels of teacher engagement. Scale internal consistency has been previously shown to be .89 with interrater reliability of .94 (Ruble \& McGrew, 2013). Sample internal consistency was .81 in the current study.

Teacher stress. Part B of the Index of Teaching Stress (ITS; Abidin, Greene, \& Konold, 2004) was used to measure teacher stress when working with a particular student. Teachers rated each of the 43 items using a 5-point Likert-type response scale (5=very distressing; $1=$ never distressing). Part B, the teacher domain, considers how the student affects the teaching process and teacher perceptions of the student. There are four subscales within Part B: self-doubt/needs support (19 items), loss of satisfaction from teaching (12 items), disrupts teaching process (6 items), and frustration working with parents (6 items). Total scores were calculated as the mean of the item scores all 43 items. Higher scores indicate higher levels of teacher stress. Internal consistency for the total scale was .96 (Abidin, et al., 2004).

Student IEP goal attainment. Psychometrically Equivalence Tested Goal Attainment Scaling (PET-GAS; Ruble, Dalrymple, \& McGrew 2010; Ruble, McGrew, \& Toland, 2012) was used to assess student outcomes. Originally developed to assess mental health services (Kiresuk and Sherman 1968), goal attainment scaling is an individualized and more sensitive measurement approach to analyze intervention outcomes as opposed to broad, standardized measurements such as intelligence or adaptive behavior (Kiresuk, Smith, \& Cardillo, 1994; Ruble, McGrew, \& Toland, 2012, Gaasterland, Jansen-van der Weide, Weinreich, \& van der Lee, 2016). Goal attainment scaling is the main student outcome measure targeted in the (REMOVED) Consultation (REMOVED). PET-GAS ratings range from -2 (present levels of performance) to +2 (much more than expected level of outcome), with a score of 0 indicating a 
student met the expected level of performance for the goal. A total GAS score was derived by averaging the total raw scores from the three student goals for each participant. An independent observer coded video tapes of the teachers performing the targeted teaching objective(s) to provide the final PET-GAS scores on student progress for each goal. During the observation, teachers demonstrated each of the targeted teaching objectives during instruction. Interrater agreement as measured using the sample ICC for single measures was .82 for the social skills, .86 for communication skills, and .91 for learning skills goals (Ruble, et al., 2013).

\section{Data Analyses}

Cross-sectional correlation analyses were used to calculate the associations between selfefficacy for teaching students with ASD, teacher stress, teacher engagement, and student achievement. A post treatment one-way factor analysis of variance (ANOVA) was used to evaluate the impact of (REMOVED) on teacher self-efficacy. Levene's test was used to test the homogeneity of variance assumption for the ANOVA. Levene's test was non-significant, $F(1$, $42)=2.10, p=.155$, suggesting that the assumption was met. To answer the first research question regarding the relationship between self-efficacy for teaching students with ASD and related variables, final scores were used. To answer the second research question, both baseline and final scores were used.

\section{Results}

Tests of hypothesized correlations. As predicted, teacher self-efficacy was significantly and positively related to teacher engagement $(r=.36, p=.008$; Table 2$)$ and student IEP goal attainment outcome scores $(r=.39, p=.005)$. That is, teachers who self-report higher levels of teacher self-efficacy were more likely to engage positively with their students with ASD and to have students with greater goal attainment. In addition, teacher self-efficacy was significantly 
and negatively related to teacher stress $(r=-.39, p=.005)$, indicating that teachers with lower self-efficacy for teaching students with ASD were more likely to report higher levels of stress.

Non-hypothesized correlations. Analyses of the intercorrelations between the rest of the variables indicated that teacher stress was significantly and negatively related to teacher engagement $(r=-.29, p=.03)$ and student IEP goal attainment outcomes scores $(r=-.26, p$ $=.044)$. That is, teachers with higher levels of stress had lower engagement and student outcome scores. Finally, teacher engagement was positively and significantly correlated with student outcome scores $(r=.38, p=.005)$.

Analysis of variance results. The goal of this analysis was to determine if there were significant differences in teacher self-efficacy for the intervention and control groups. The ideal analysis for this question would have been an ANCOVA controlling for baseline scores; however, assumptions of homoscedasticity were not met due to the small sample size and an ANOVA became the most appropriate test. Although the ANOVA of interest was performed on the final scores, baseline scores were also checked to ensure there was no difference in groups at the beginning of the intervention. Results indicated there was no significant difference between groups at baseline, $F(1,42)=1.57, p=.23$. The post-treatment ANOVA indicated a statistically significant difference between the experimental $(M=84.7, S D=9.3, n=29)$ and control groups $(M=77.1, S D=11.8, n=15)$ using final scores, $F(1,42)=5.12, p=.029, \square^{2}=0.11$, suggesting that approximately $11 \%$ of the variability in teacher self-efficacy scores could be accounted for by the differences among the two group means.

\section{Discussion}

We examined the strength of relationship between self-efficacy for teaching students with ASD and teacher stress, teacher engagement, and student IEP goal attainment. Results indicated 
a positive and significant relationship between self-efficacy, engagement, and student IEP goal attainment. Teachers who believed they could teach students with ASD also were more likely to engage positively with their students with ASD and those students achieved higher student IEP goal attainment outcomes. These results are consistent with prior research reporting positive associations between teacher self-efficacy and student achievement in general education (Zee \& Koomen, 2016). The current study extends that relationship to special education using a measure of student outcomes appropriate for students with individualized educational programs. In addition, previous work has shown that teacher self-efficacy is correlated with engagement (Klassen, Yerdelen, \& Durksen, 2013; Skaalvik \& Skaalvik, 2014). The current study once again extends these findings to the special education setting. Moreover, the focus on children with ASD helps to provide further information that can be applied to this specific group of learners. Future studies should assess the directionality of these findings and explore how self-efficacy may lead to higher teacher engagement.

Another finding was that teacher stress was negatively related to self-efficacy. That is, teachers who are less stressed also report higher levels of self-efficacy for teaching students with ASD. This is consistent with previous studies reporting a decrease in teacher stress and an increase in coping when teacher self-efficacy increases (Zee \& Koomen, 2016). In addition, these findings are consistent with results from Ruble, Usher and McGrew (2011) and Ruble and colleagues (2013) that teacher burnout was negatively associated with teacher self-efficacy for teachers of those with ASD. It is plausible that teacher self-efficacy acts as a protection against teacher stress; that is, teachers who believe they can support their students with autism are less likely to be effected by the stress of teaching a student with autism. However, further study will be needed to confirm this hypothesis. 
Because these data are a part of a larger RCT (REMOVED), it was important to evaluate results in terms of intervention and control groups because the intervention may have impacted teacher self-efficacy, our domain of interest. Results from an ANOVA ominous $F$ test indicated that teachers in the experimental group who had the intervention reported higher levels of teacher self-efficacy after the intervention. While the increase in teacher self-efficacy was minimal, these results serve as confirmation that (REMOVED) had a bearing on teacher's capability beliefs to teach their students with ASD. According to Bandura (1997), there are four sources of selfefficacy: mastery experiences, vicarious experiences, social persuasions, and physiological responses. Although (REMOVED) did not target teacher self-efficacy directly, three of these four sources of self-efficacy were embedded within the intervention. As noted earlier, mastery experiences were provided as teachers received feedback on the implementation of teaching plans through videotape, reflection of themselves during coaching sessions, and performance based outcome analysis. Social persuasions were given within consultation sessions as the coaches provided encouragement and support. Physiological responses such as stress and anxiety were addressed through the support provided during the coaching sessions as teachers the instructional plans. These results suggest that although the intervention did not target these variables directly and was aimed at supporting teachers in goal setting, intervention development, and outcome monitoring, interventions like the (REMOVED) Consultation may have the potential to be successful in improving teacher belief. However, experimental and quasi-experimental designs that target teacher self-efficacy specifically are infrequent, according to a review of teacher self-efficacy research (Klassen, Tze, Betts, \& Gordon, 2011). Zee and Koomen (2016) insist that experimental studies and longitudinal designs are needed to further 
develop and understand self-efficacy, and this study serves as justification for furthering the use of interventions, specifically consultation interventions, that can improve teacher self-efficacy.

Another contribution of the study was the use of a population specific measure of selfefficacy. Population specific measures have the advantage of increased sensitivity in detecting effects. Thus, in the current study, we used a self-efficacy measure specific to the population of teaching students with ASD. This is a crucial methodological contribution because a recent review indicated that too many studies are incorrectly using general teacher self-efficacy instruments (Zee \& Kooman, 2016). Moreover, use of general measures is in direct disagreement with Bandura (1997) who framed self-efficacy as a construct that changes depending on the population and construct.

These results have important implications for the classroom. Teacher self-beliefs are likely to have a significant impact on teachers' decisions, teaching environment, and interactions with students with ASD. That a relationship between these variables was identified strengthens the importance of teacher belief as an area of research and of intervention and informs future experimental and intervention research aimed at addressing areas where teachers feel incompetent. The study also included a measure of student goal attainment that is appropriate for students with individualized learning plans within special education, and supports future work using such an achievement indicator.

Grant Acknowledgement

This work was supported by Grant 1RC1MH089760 from the National Institute of Mental Health. 


\section{References}

Abidin, R., Greene, R., \& Konold, T. (2004). Index of teaching stress. Psychological Assessment Resources. Florida: Lutz.

Allinder, R. M. (1995). An examination of the relationship between teacher efficacy and curriculum-based measurement and student achievement. Remedial and Special Education, 16(4), 247-254.

American Psychiatric Association. (2000). Diagnostic and Statistical Manual of Mental Disorders (4 ${ }^{\text {th }}$ edition, text revised). Washington, DC: American Psychiatric Association.

Anderman, L., \& Klassen, R. (2015). Being a teacher: Efficacy, emotions, and interpersonal relationships in classroom settings. In L. Corno, \& E. M. Anderman (Eds.), Handbook of Educational Psychology. (3rd ed., pp. 402-414). Routledge.

Bandura, A. (2006). Guide for constructing self-efficacy scales. In F. Pajares \& T. Urdan (Eds.), Self-efficacy beliefs of adolescents (pp. 307-337). Charlotte: NC: Information Age Publishing.

Bandura, A. (1997). Self-efficacy: The exercise of control. New York, NY: W. H. Freeman and Company.

Coladarci, T., \& Breton, W. A. (1997). Teacher efficacy, supervision, and the special education resource-room teacher. The Journal of Educational Research, 90(4), 230-239.

Fives, H., \& Buehl, M. M. (2008). What do teachers believe? Developing a framework for examining beliefs about teachers' knowledge and ability. Contemporary Educational Psychology, 33(2), 134-176. 
Gaasterland, C. M., Jansen-van der Weide, M. C., Weinreich, S. S., \& van der Lee, J. H. (2016). A systematic review to investigate the measurement properties of goal attainment scaling, towards use in drug trials. BMC Medical Research Methodology, 16(1), 99.

Individuals with Disabilities Education Act. (2004). Retrieved from http://idea.ed.gov/explore/view/p/\%2Croot $\% 2 C$.

Jennett, H. K., Harris, S. L., \& Mesibov, G. B. (2003). Commitment to philosophy, teacher efficacy, and burnout among teachers of children with autism. Journal of Autism and Developmental Disorders, 33(6), 583-593.

Kiresuk, T. J., \& Sherman, R. E. (1968). Goal attainment scaling: A general method for evaluating comprehensive community mental health programs. Community Mental Health Journal, 4, 443-453. doi:10.1007/BF01530764.

Kiresuk, T. J., Smith, A., \& Cardillo, J. E. (1994). Goal attainment scaling: Applications, theory, and measurement. Hillsdale, NJ, England: Lawrence Erlbaum Associates, Inc.

Klassen, R. M., \& Tze, V. M. (2014). Teachers' self-efficacy, personality, and teaching effectiveness: A meta-analysis. Educational Research Review, 12, 59-76.

Klassen, R. M., Tze, V. M., Betts, S. M., \& Gordon, K. A. (2011). Teacher efficacy research 1998-2009: Signs of progress or unfulfilled promise? Educational Psychology Review, 23(1), 21-43.

Klassen, R. M., Yerdelen, S., \& Durksen, T. L. (2013). Measuring teacher engagement: development of the engaged teachers scale (ETS). Frontline Learning Research, 1(2), 3352.

Lord, C., Risi, S., Lambrecht, L., Cook, E. H., Leventhal, B. L., DiLavore, P. C., Pickles, A., \& Rutter, M. (2000). The Autism Diagnostic Observation Schedule—Generic: A standard 
measure of social and communication deficits associated with the spectrum of autism. Journal of Autism and Developmental Disorders, 30(3), 205-223.

National Research Council. (2001). Educating children with autism. Washington, DC: National Academy Press.

Pajares, F. (1996). Self-efficacy beliefs in academic settings. Review of Educational Research, $66(4), 543-578$.

Ross, J. A. (1992). Teacher efficacy and the effects of coaching on student achievement. Canadian Journal of Education, 17, 51-65. doi:10.2307/1495395

Ruble, L. A., Dalrymple, N. J., \& McGrew, J. H. (2010). The effects of consultation on individualized education program outcomes for young children with autism: The collaborative model for promoting competence and success. Journal of Early Intervention, 32, 286-301. doi:10.1177/1053815110382973.

Ruble, L., Dalrymple, N. J., \& McGrew, J. H. (2012). Collaborative model for promoting competence and success of students with autism. NY: Springer.

Ruble, L., \& McGrew, J. (2013). Teacher and child predictors of achieving IEP goals of children with autism. Journal of Autism and Developmental Disorders, 43, 2748-2763.

Ruble, L. A., McGrew, J. H., Toland, M. D., Dalrymple, N. J., \& Jung, L. A. (2013). A randomized controlled trial of COMPASS web-based and face-to-face teacher coaching in autism. Journal of Consulting and Clinical Psychology, 81(3), 566.

Ruble, L., McGrew, J. H., \& Toland, M. D. (2012). Goal attainment scaling as an outcome measure in randomized controlled trials of psychosocial interventions in autism. Journal of Autism And Developmental Disorders, 42(9), 1974-1983. doi:10.1007/s10803-012$1446-7$ 
Ruble, L. A., Toland, M. D., Birdwhistell, J. L., McGrew, J. H., \& Usher, E. L. (2013). Preliminary study of the autism self-efficacy scale for teachers (ASSET). Research in Autism Spectrum Disorders, 7(9), 1151-1159. doi:10.1016/j.rasd.2013.06.006

Ruble, L. A., Usher, E. L., \& McGrew, J. H. (2011). Preliminary investigation of the sources of self-efficacy among teachers of students with autism. Focus on Autism and Other Developmental Disabilities, 26(2), 67-74.

Segall, M. J., \& Campbell, J. M. (2014). Factors influencing the educational placement of students with autism spectrum disorders. Research in Autism Spectrum Disorders, 8(1), $31-43$.

Skaalvik, E. M., \& Skaalvik, S. (2014). Teacher self-efficacy and perceived autonomy: Relations with teacher engagement, job satisfaction, and emotional exhaustion. Psychological Reports, 114(1), 68-77.

Tefera, A., Thorius, K. K., \& Artiles, A. J. (2014). Teacher influences in the racialization of disabilities. In H.R. Milner IV \& K. Lomotey (Eds.), Handbook of Urban Education (pp. 256-270). New York, New York: Routledge.

Usher, E. L., \& Pajares, F. (2008). Sources of self-efficacy in school: Critical review of the literature and future directions. Review of Educational Research, 78(4), 751-796.

White, M. L., Smith, J. D., Smith, T. E. C., \& Stodden, R. (2012). Autism spectrum disorders. In D. Zager, M. L. Wehmeyer, \& R. L. Simpson (Eds.), Educating students with autism spectrum disorders (pp. 3-12). New York, NY: Routledge.

Zee, M., \& Koomen, H. M. (2016). Teacher self-efficacy and its effects on classroom processes, student academic adjustment, and teacher well-being: A synthesis of 40 years of research. Review of Educational Research, 86(4), 981-1015. 
Table 1

Teacher and Student Demographics

\section{Frequency Percentage}

\section{Student Characteristics $(N=44)$}

Gender

Male

37

84.1

Female

7

Teacher Characteristics $(N=44)$

Gender

Male

1

Female

43

97.7

Education

Bachelor's Degree

22

Master's Degree

19

46.3

Primary Teaching Role

Special Education

21

50.0

Special Education Preschool Teacher

13

19.0

Special Education Resource ${ }^{\mathrm{a}}$ Teacher

8

31.0

$M$

$S D$

Teaching Experience

Years Teaching

11.3

8.2

Years Teaching Students with ASD

5.71

5.7

Class Size

12.4

5.3 
Note. ${ }^{\text {a}}$ Resource classrooms are separate individual or small group settings where instruction is delivered outside of the general education classroom, sometimes referred to as "pull out" instruction. 
Table 2

Pearson's Correlations for Variables in the Study

\begin{tabular}{lccc}
\hline & Teacher Self- & Teacher & Teacher \\
& Efficacy & Stress & Engagement \\
\hline Teacher Stress & $-.39 * *$ & & \\
Teacher Engagement & $.36^{* *}$ & $-.29 *$ & $.38^{* *}$ \\
Student IEP Goal Attainment & $.39^{* *}$ & $-.26^{*}$ & \\
\hline
\end{tabular}

Note. ${ }^{*} p<.05 .{ }^{* *} p<.01 .{ }^{* * *} p<.001$ for all analyses 